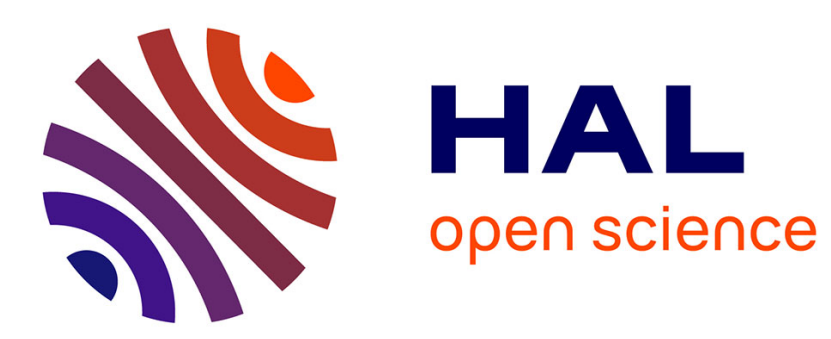

\title{
Untangling fear and eudaimonia in the healthcare provider-patient relationship
}

Brenda Bogaert

\section{To cite this version:}

Brenda Bogaert. Untangling fear and eudaimonia in the healthcare provider-patient relationship. Medicine, Health Care and Philosophy, 2020, 23 (3), pp.457-469. 10.1007/s11019-020-09956-1. sic_03109479

\section{HAL Id: sic_03109479 \\ https://archivesic.ccsd.cnrs.fr/sic_03109479}

Submitted on 13 Jan 2021

HAL is a multi-disciplinary open access archive for the deposit and dissemination of scientific research documents, whether they are published or not. The documents may come from teaching and research institutions in France or abroad, or from public or private research centers.
L'archive ouverte pluridisciplinaire HAL, est destinée au dépôt et à la diffusion de documents scientifiques de niveau recherche, publiés ou non, émanant des établissements d'enseignement et de recherche français ou étrangers, des laboratoires publics ou privés. 


\title{
Untangling Fear and Eudaimonia in the Healthcare Provider-Patient Relationship
}

\begin{abstract}
Ensuring patient participation in healthcare decision making remains a difficult task. Factors such as a lack of time in the consultation, medical objectivation, or the difficulties of translating individual patient experience into the treatment plan have been shown to limit patient contributions. Little research attention has focused however on how emotions experienced by both the patient and the healthcare provider may affect the ability of the patient to participate. In this research, patient's and healthcare provider's emotions were identified and analysed. The research method showed fear as a prominent emotion experienced. This included patient's fears both inside and outside the consultation, as well as the healthcare provider's fears in their professional practice. Using Martha Nussbaum's cognitive-evaluative theory of emotions as an additional means of analysis, the research looked at what this emotion could show about the importance of the object of this fear to the person's eudaimonia (flourishing). At the end of the article, several solutions were proposed to help mitigate this fear to keep it from becoming a destructive force in the healthcare provider - patient relationship.
\end{abstract}

\section{Keywords}

Emotions; Nussbaum; France; qualitative research; doctor-patient communication

\section{Introduction}

With the call for greater patient participation in health democracies, new forms and models of patient participation are emerging. Patient expert programmes are being promoted as a means of reversing the asymmetrical patient-doctor relationship by having patients become teachers to future doctors (Karazivan et al. 2015). Patient associations are playing an increasingly political role in healthcare policy development and implementation, with integration into both formal and informal cadres of patient support (Callon and Rabeharisoa 2008). Approaches such as patient-centered care have attempted to correct tendencies for healthcare to be either too disease-centered or too staff/system centered by seeking to put the patient at the center of the healthcare plan (Entwistle and Watt 2013).

However, despite all of these developments, the doctor-patient relationship continues to be conflictual for both the doctor and the patient. Much patient dissatisfaction is due to breakdowns in the doctor-patient relationship (Ha and Longnecker 2010). Conflictual patient-doctor relationships have also been associated with poor healthcare outcomes and medical errors (Chipidza et al. 2015). Physician burn-out is also becoming an increasing problem, leading to inadequate patient participation, medical errors, and poor healthcare outcomes (Dyrbye and Shanafelt 2011). As the doctor-patient relationship is a complex topic that means different things to different people, research in the area remains fragmented (Ridd et al. 2009). Historically, most research tends to focus on facets of the consultation such as the communication and interpersonal skills of the doctor (Stewart 1995 ) or the characteristics of a successful relationship, such as trust (O’Neill 2002).

The emotions patients experience in the diagnosis and treatment of various chronic diseases are fairly well developed in empirical literature (Del Piccolo et al. 2005; Keddie et al. 2016; Gumuchian et al. 2016). These kinds of studies have given tools for the healthcare practioner to work with patients' emotions in clinical practice. However the predominance of studies on patient's emotions may unintentionally link patient emotions with characteristics such as emotional instability, making them appear less epistemically credible (Carel and Kidd 2014).

While some studies have focused on emotions experienced by healthcare professionals, in particular in relation to end of life care (Redinbaugh 2003) or the shame and guilt experienced by doctors due to medical errors (Sirriyeh et al. 2010), most research on healthcare providers' emotions remains anecdotal. This is thought to be in part because emotions are still considered as unprofessional or taboo among healthcare professionals (Silva and Carvalho 2016). This study therefore sought to uncover what emotions were experienced by both healthcare professionals and patients in order to understand how these emotions might affect the healthcare alliance.

\section{Theoretical Framework}

The theoretical framework used in this study was American philosopher Martha Nussbaum's cognitiveevaluative theory of emotions. While philosophers have conceptualized emotions for thousands of years, recent research has provoked a reconfiguration in the idea that emotions imply thinking, judgment, or evaluation. Nussbaum has made an important contribution to this field of study, most notably with her book, Upheavals of Thought: the Intelligence of Emotions (2003). Rather than seeing emotions as irrational or problematic, she advances the idea that emotions are part of our system of ethical reasoning. Nussbaum (2003, p. 4) defines 
emotions as, "appraisals or value judgments, which ascribe to things and persons outside the person's own control great importance for that person's own flourishing." She argues that emotions always involve thought of an object combined with the object's salience; thus they always involve appraisal/evaluation. This is what she calls her cognitive-evaluative view (2003, p. 23). For Nussbaum, it is not that emotions have a cognitive component more than other elements, but rather that they are cognitions and that these cognitions are necessary and sufficient (Nussbaum 2003, p. 34).

To account for these propositions, Nussbaum proposes a Neo-Stoic reformulation of emotions as judgments. She says this judgment has two stages. In the first stage, one thinks that things are that way, or to use her words, it "occurs" or "strikes the person" but the person has not really accepted them as they are. There follows several possibilities, which she calls "judgments" in which one can either accept or embrace these appearances. These judgments transform into beliefs about the way things are (Nussbaum 2003, p. 37). Nussbaum specifies that this action (assenting/rejecting/absence of judgment) is an act of cognition. It is therefore a form of reasoning, in which the person assesses the situation and makes a judgment about its importance.

For Nussbaum, "emotions...insist on the real importance of their object, but they also embody the person's own commitment to the object as part of her scheme of ends." (Nussbaum 2003, p. 33) Emotions are concerned with value. They are connected with our eudaimonia (flourishing), as the object of the emotion will show something of importance about the life of that person (Nussbaum 2003, p. 30). In addition, because this judgment is related to one's eudaimonia, then it is not necessarily possible to preserve emotional equanimity when we experience emotions (Nussbaum 2003, p. 41). In making this claim, Nussbaum gives particular salience to the intensity of the emotion. The difference of intensity of an emotion can be explained by the importance with which the person invests in the object among their own goals and projects (Nussbaum 2003, p. 55). This intensity may therefore give clues about objects of particular importance to the person's flourishing.

Nussbaum also shows that emotions are "cognitively laden" in that they have a connection to imagination that differentiates them from more abstract judgements (Nussbaum 2003, p. 40). This helps explain how our emotions can change: an object of fear, for instance, in one situation can become magnified or distorted into a new fear when we "imagine" a past event: imagination therefore helps us take on significance not immediately apparent in that situation. We will see how imagination can affect emotions in the consultation when we examine the patient's fears.

Nussbaum completes her cognitive-evaluative view by looking into the origins of our emotions in infancy and why we feel intense emotions in certain situations. She says that infants experience their first emotions when they develop an awareness of their need for external objects (persons or things) in order to survive. This realization creates feelings of ambivalence, as we need these things in order to survive, but do not wish to have this need. This can lead to intense emotions such as fear as the provision of these external goods is uncertain. For the infant there is, "one overwhelming emotion (which has) a formative influence on daily life...fear." (Nussbaum 2018, p. 23). These strong emotions stemming from our vulnerabilities and need for others are not only limited to these periods in our lives. The experience of illness is one situation when our need for external objects comes to a forefront and is thus therefore often a time when we experience fear.

Nussbaum has characterized fear as an intense emotion that we feel in the presence of some danger or harm. Sometimes this object has a clear relationship to one's survival (such as being afraid of being bitten by a snake), but fears can also take a vague form, such as one's place in society. However, fear is usually directed at some kind of object and usually involves some action to "release the fear" or "get out of danger." Fear is different from anxiety, which refers to knowledge of a poorly defined threat and does not necessarily implicate an action (Corbeil 2001, p. 29). In this article, we will focus specifically on the emotion of fear over anxiety as it is the emotion that patients themselves have identified as important. We will also pay attention to any actions which may result from this emotion.

In summary, our emotions enable us evaluate objects and their importance to us, but they also highlight our vulnerabilities and need for others. Even emotions that are seen as negative, such as fear, help us evaluate what is of concern to our lives, by showing what is at threat but also of particular importance. As often the object of our emotions is people and our relationships with them, our emotions are often related to whether we can flourish with the help of these relationships. Nussbaum's theory will help to unravel emotions experienced in the therapeutic alliance and what they will show about the values of the healthcare provider and the patient.

However, one limitation of Nussbaum's cognitive-evaluative view will need to be highlighted before continuing. Although Nussbaum agrees that although emotions are also bodily, she objects to their claim to be a necessary condition for that emotion. She argues, "emotions cause physiological effects: so it is extremely difficult to say which effects are consequences and which are even plausible candidates for being parts of the experience itself (Nussbaum 2003, p. 58)." The debate on the necessarily phenomenological component of emotions is ongoing. However, because of her emphasis on emotions as cognitive evaluations, she has not adequately taken into account how the phenomenological character of emotion can also influence our judgements. In the past few years, theorists have attempted to balance the bodily and cognitive viewpoints into 
different hybrid theories (see Maiese 2014, Gunther 2004). Scientific studies have also led weight to these hybrid theories, showing us how emotions prepare us to meet the challenges in our environment through adjustments in skeletomuscular, neuroendocrine, and the autonomic nervous systems (Nummenmaa 2014). What emerges from these studies is that bodily expressions of emotions are interlinked to cognitive evaluations and help the person to make judgments about objects. As the bodily experience is connected with the evaluation of eudaimonia and gives us clues of its importance for the person concerned, it will also be a part of our analysis when we examine the patient's fear.

\section{Methodology}

The target group for this study was refractory epilepsy patients in France and the healthcare providers treating them. Epilepsy is a chronic, neurological disease that even today remains largely misunderstood. It presents in the form of seizures, but the diversity of causes, syndromes, and types of seizures are extensive, making it difficult to diagnose and treat. While around $70 \%$ of patients are able to stabilize their seizures, about one-third cannot fully eliminate seizures from their lives due to currently available treatments. These refractory epilepsy patients live with considerable uncertainty as they do not know when seizures will happen or how they will evolve in time. In addition, despite growing awareness of epilepsy as a neurological disorder, epilepsy also remains stigmatized due to ongoing misrepresentations of the disease as contagion or a psychiatric illness (de Boer 2010). Because it is a particularly difficult chronic disease to treat, but also to live with, identifying the key emotions that may affect patient care may be able to help these patients to live better with their disease, as well as improve treatment plans.

A researcher with a dual background in philosophy and sociology designed and led the research project. The researcher is a member of the University of Lyon III Research Chair in the Values of Patient Centred Care and a lecturer at the University of Lyon 1 medical school. It was conducted as a research project from 2016-2019 to better understand patient care for epilepsy patients in France. The necessary declarations to the National Commission for Informatics and Liberty (Commission Nationale de l'Informatique et des Libertés or CNIL) were made and consent was obtained from participants prior to the start of the research.

Using a pragmatic approach, the research methods were developed specifically for the research project and for the group of patients based upon their desires and capacities to participate. The research took place in three sites of informal and formal healthcare delivery, consisting of two patient associations in France in two different cities and one hospital specialized in refractory epilepsy patient care. In the first stage of the research, a focused ethnography approach (as informed by Bikker et al. 2017 and Rashid et al. 2019) was used in order to better understand the healthcare environment for epilepsy patient care. The aim of the focused ethnography stage was to witness how actors (healthcare providers and patients) discussed their relationships with either their healthcare provider or their patients, as well as to witness interactions in the hospital service and in the consultation room. The focused ethnography stage consisted of short term punctual data collection via participant observation in two patient association meetings in two different cities in France for a period of one year. It also took place through several full days at a hospital specialized in epilepsy care, shadowing healthcare workers, observing informal conversations between them and other workers and in their interactions with their patients. This also included attending informal and formal multidisciplinary staff meetings and consultations with patients in order to understand how they spoke of and interacted with patients. A field notebook was kept in order to witness surprises, remarks, or key words that were used during the conversations among patients/families and their healthcare providers.

The second stage of the research consisted of in-depth interviews. The aim was to obtain a richer understanding of topics discussed during the focused ethnography stage. As the methodology of in-depth interviews solicits the participant's experience, feeling, or behavior and combines structure with flexibility (Ritchie and Lewis 2014), it allowed the researcher to focus the interview on the subject of interest, but also to allow the participant to lead the topics discussed. The in-depth interviews, conducted with 19 refractory epilepsy patients focused on a descriptive research question: please tell me about your epilepsy? Follow-up probes were asked depending on the responses by the patients, including asking about their opinions and feelings about their medical care, their family environment, and what patients wanted to achieve in their lives despite their epilepsy, to better understand the patient's responses. Although emotions were not specifically solicited by the researcher in order to avoid bias, when emotions were described, the researcher asked follow-up questions to better understand the meaning of the emotion with the person interviewed.

Given the diversity of complex social and psychological needs of epilepsy patients, the healthcare provided for refractory epilepsy patients in France sometimes includes consultations with a neurologist, but also increasingly specialized epilepsy nursing care combined with psychological and social support. Therefore in the second stage of the research project, ten healthcare providers representing these diverse healthcare professions 
(psychiatry, nursing, social work) were interviewed in order to solicit their perspectives on epilepsy patient care. The research question to healthcare providers was similar to those with patients: please tell me about your work with epilepsy patients? As with patient-led interviews, healthcare provider's own emotions were not specifically solicited by the researcher; however, when this topic was brought up, the researcher asked follow-up questions to better understand the context and meaning of the emotion expressed. As these interviews were conducted at the same time as the patient interviews, the interviewer also asked healthcare providers to comment on the emotions expressed by patients toward them.

In the analysis stage, both the notes taken during the ethnography and interview stages as well as the transcriptions of the interviews were analyzed by means of qualitative tools. An intuitive process described by Taylor and Bogdan (1998, p. 130-136) helped inform the analysis. It included looking for themes by examining the data in as many ways as possible, including by reading and rereading the interviews/field notes, listening to the interview transcriptions, keeping track of ideas/themes/surprises, looking for emerging themes, reading international literature on the topic to spot correlations/variations, etc. The healthcare and patient's interviews were also analyzed separately to avoid bias. The results were also discussed with study participants (including healthcare providers) and in university research seminars to help refine the analysis.

The analysis allowed identification of emotions, and in particular of fear, as an important theme both for healthcare providers and for patients. Therefore, an additional analysis was conducted to better understand how patients and healthcare providers described this emotion, why and in what context, or if it involved certain persons. After having identified this emotion, the data was contextualized in order to have a better understanding of the emotions expressed and if it led to any particular actions, as well as the different interpretations of these emotions among actors. As a final part of the analysis, the researcher sought to further understand the emotion with the input of Martha Nussbaum's theory of emotions.

\section{Results}

The research gathering and analysis stage showed the predominance of the emotion of fear across all sites in both the focused ethnography and in-depth interview stages of the research. Patients specifically used the word fear over other possible evaluations such as anxiety or apprehension to describe living with epilepsy. Patients often used the word "fear" to describe situations they dealt with in daily life with their disease, such as the fear of having a seizure in public. Fear was also described by patients in their interactions with others, including with their family, society, and their healthcare providers. Patients specifically used the word fear to describe certain encounters with healthcare providers, both in reference to themselves (they were scared of giving certain details to the healthcare provider), or witnessed in their healthcare provider.

While emotions expressed in the consultation were described more ambivalently by healthcare providers, fear and/or apprehension was cited to describe the difficulty of communicating the uncertainty, bad news, and/or the failure of a treatment plan to patients and their families. While most described these emotions when speaking about their colleagues (rather than themselves), they openly admitted that such emotions were prevalent in healthcare. Even more, they said that such kind of emotions led to concrete actions affecting their relationships with patients, in particular "hiding" behaviors such as not giving full information on the treatment plan. One healthcare provider used the word "apprehension" rather than fear, thus expressing a more vague fear, poorly defined, rather than one punctuated by a period of crisis. The implications of such an assessment in light of Nussbaum's theory will be elaborated in the discussion section.

\section{The Patient's Fear}

For patients participating in this research project, fear was a prominent emotion experienced in their overall lives. They specifically focused on the psychosocial impact of living with seizures when discussing their epilepsy. This result concurs with empirical research that shows a link between fear and anxiety for persons with epilepsy due to neurological, pharmaceutical, and psychosocial factors of living with the condition (Vazquez and Devinksky 2003). The word "fear" was openly used among patients and families in patient associations meetings in reference to their disease and society's treatment of them.

The emotion of fear was also openly discussed during in-depth interviews in response to the question, "please tell me about your epilepsy." Patients often describe living with epilepsy as "living with a sword of Damocles" above their heads. Their lives consist of considerable uncertainty: when will a seizure occur? Who will they be with? How will others react to their seizures? What will others do to them while they are seizing? What might their body do that could hurt others and themselves? This knowledge of moments of a lack of control of the body causes fear for many persons with epilepsy. Their life with epilepsy is an ongoing negotiation with fear, including fear of seizures past but also of those to come.

For patients, this emotion was principally expressed in reference to fear of their bodies. As the body loses control during seizures, the body becomes a risk. The body can both be harmed and/or cause harm during a seizure, and the person with epilepsy sometimes loses consciousness and "wakes up" to discover what their 
bodies did during the seizure. During the period of the seizure, patients described themselves as "helpless" and were fearful of what would happen to them. Some patients described their bodies as "other" during a seizure, as an object of fear both for themselves and for witnesses. For patients who did not lose consciousness during their seizure, but who were witness to their body derailment and unable to intervene, they described this body disconnect as "horrific" or even "painful" due to this loss of control.

Another fear consistently voiced by patients was fear of how others would react during the seizure. Given the low societal awareness of how to help the person with epilepsy into safety, patients related stories of strangers reacting in a way that put the person having the seizure at risk, such as putting an object in their mouth, or not moving them into a secure position. This made them fearful of having a seizure in public, as it could put them at risk due to the intervention of others.

There was also the fear of disclosing their epilepsy in a wider social context. Patients in both the in-depth interviews and patient association meetings frequently discussed the "fear" of disclosing their epilepsy to others, should it be friends, potential partners, or future employers. Patients expressed fear that disclosure would lead to stigmatization or discrimination against them. Fear of disclosing their epilepsy to their future employers was among the most popular themes of patient association meetings and was subject to contentious debate of how to address it, in particular in the workplace. This fear is not without foundation. Fear of disclosing epilepsy concurs with empirical research which shows links between epilepsy and higher rates of unemployment and underemployment, as well as greater difficulties in job retention due to stigma and discrimination (Smeets et al. 2007, p. 354). Because of these factors, until recently, healthcare providers have encouraged patients to hide their epilepsy from potential employers. Now however, more and more healthcare providers, as well as patient associations are encouraging patients to "tell" their epilepsy so that society can become more aware of the condition. Still, patients expressed fears to openly disclose their condition, in particular in the workplace, due to potential stigma and/or discrimination.

The patient with epilepsy has to mitigate considerable fear on a daily basis given the unpredictability of their disease, the uncertainty of the assistance of others, and perceived and felt social stigma. Given the considerable fear lived by the patient, the relationship between patient and doctor can be a privileged relationship. The doctor can be one of the few who "knows" and "understands" the disease. As Irving Goffman said, the doctor is that "sympathetic other" that sees the disease as ordinary (1968, p. 31). Therefore the patient should not be scared to interact with the doctor about their disease. However, this encounter is also problematic for the patient because it is often a relationship of fear for both the patient and their doctor.

\section{Fear in the Doctor-Patient Relationship}

In patient association meetings, a common topic of discussion in the two groups was relationship difficulties with healthcare providers, in particular with their neurologists. Patients complained about their lack of participation in the treatment plan or neurologists not listening to them or taking concerns about the side effects of their treatment lightly. In the in-depth interviews, a few patients also discussed their fears of medical authority and a reticence to reveal details of their disorder and treatment. Some did not feel comfortable because it meant revealing embarrassing side effects of their illness or treatment, such as psychological problems, behavioral problems, or social problems. These difficulties were seen as "embarrassing" and patients said they did not want to share this information with their doctor. Other patients were scared of giving potentially useless information to their neurologist and making them lose their time. Patients who sought out complementary activities, such as sports or hobbies to reduce stress, even when encouraged by their healthcare provider, often did not share this information with their neurologist for fear of the information being seen as "silly" or "irrelevant" from a medical perspective. Patients in both the in-depth interviews and patient meetings openly voiced fears of communicating these kinds of details to their doctors, although for diverse reasons.

Some patients however also described fears witnessed in their healthcare provider. They said in particular that their doctors were scared of openly discussing with them the treatment plan. According to these patients, this was because the treatment was uncertain and/or the healthcare provider could not provide an adequate solution to completely stop their seizures. According to patients, this uncertainty or failure put the epistemic authority of the doctor into question. One patient expressed this as, "it's the capacity to put oneself under scrutiny, that is not easy...this is about ego, somewhat. But it's also fear to put oneself under scrutiny. Fear." According to these patients, these expressions of fear coming from doctors were problematic: they led to concrete actions, including hiding information on the treatment plan or on side effects from patients. Concretely, for patients this meant that they were not adequately informed or did not participate as much as they could have otherwise in deciding the treatment plan.

These descriptions of the fear manifested by the doctor and witnessed by the patients were often described in a visual way. When patients spoke in either patient groups or in the interviews of this fear, they often described non-verbal behavior as evidence of their fear, such as "he stared at his computer, rather than at me, " or "he did not look me in the eyes." As humans, our visual contact remains an important means to connect to others. In contrast to other species, our social interactions depend on these visual contacts and our mutual 
visual contacts create and show attention and interest. Patients evaluated this lack of visual contact and recognized it as fear.

According to these patients, this fear stemming from the doctor led to inadequate treatment plans and a reduced possibility for them to participate in healthcare decision making. This was because the doctor did not share information or did not solicit their patient's perspective on the treatment. In contrast, patients who spoke positively about their relationship with their healthcare providers did not describe fears either lived by themselves or witnessed in the healthcare professional. These patients said that they were able to participate in deciding the treatment plan and did not hesitate to share information with their healthcare provider. They also said that this was made possible because the doctor was open about the uncertainty or failure of the treatment plan. By such an admission, these patients said that they felt less scared of medical authority and were also able to communicate more openly with their doctor, giving them more say into treatment decisions.

Another fear discussed by patients in the evaluation of their doctor's fears was in relation to risk. Patients said that some doctors were "fearful" of making the wrong treatment decision, especially a treatment which is experimental or which can put the patient at risk due to unknown side effects. According to these patients, this fear made doctors "play it safe" by proposing a less risky treatment. For these patients, this action was unacceptable, as it prevented them from trying out experimental treatments which might be the "magic solution" to stabilize their seizures. From the patient's perspective, the problem with this expression of fear was the action resulting from the expression of the emotion. They interpreted the action of "playing it safe" as an action resulting from fear, rather than caution or non-maleficence. This emotion was a problem to be resolved from the patient's perspective as it could lead to unsatisfactory treatment plans.

\section{Healthcare Providers' Emotions}

In contrast to patients, who frequently used the word "fear" to discuss diverse aspects of their lives, including in the healthcare consultation, healthcare professionals' emotions were less openly expressed in the interviews. While most healthcare providers in the in-depth interview part of the research project did discuss emotions, this was often in reference to their patients or the emotions they witnessed in other healthcare providers, rather than themselves. While one professional said, "we do not escape emotions in human professional fields, " these responses suggest the ambivalent relationship that healthcare providers had to the role of emotions in their professional practice. Emotions experienced by healthcare professionals were mostly described as negative, leading professionals away from achieving high levels of performance in their professions, as well as causing ineffective professional relationships with their colleagues and patients. One healthcare provider stated that he encouraged his patients and other healthcare providers to take "reasoned choices" not "emotional ones"; and he saw his role partly as helping his patients and other healthcare providers control their emotions to enable them to work together. Another stated that he tried to help his co-workers toward a "professional" attitude in order not to be "led by emotions."

However, there were two temporalities in which healthcare provider did openly use the word "fear" or at least "apprehension" in terms of their relationships with their patients. The first was when it came to the difficulties of describing bad news in the consultation, such as admitting failures in the treatment plan or having to give other types of bad news to their patients. One professional expressed this as, "we are scared that (negative) information will destabilize them. We are scared that it will cause other pathologies or anxieties." This fear cited by the healthcare provider was related to the nocebo effect that certain information could have on their patients and the difficulties for the healthcare provider to deal with patients' emotions in these situations.

Another difficult temporality for the healthcare provider was the decision on the treatment plan. Epilepsy is a complicated chronic disease which challenges the doctor's expertise and authority. Most epilepsy treatments are trial and error, and patients in the interviews described themselves either as a "mystery" to their doctor or as a "guinea pig" because of this trial and error process to find the right treatment for their individual epilepsy. Doctors stated that it was difficult to admit this uncertainty and/or failure to patients, their families, and other healthcare providers, and could be a source of fear or apprehension toward their patient and/or other healthcare professionals. Doctors are seen as epistemic authorities in disease treatment by patients, healthcare organizations, and society; however, this puts pressure on doctors in particular to be able to "stop" or even "cure" the disease. When they were unable to do so, it can cause emotions such as fear, as it puts into difficulty their identities as experts.

According to healthcare providers, these fears and/or apprehensions about communicating uncertainty or the failure of the treatment plan sometimes made it difficult to communicate freely with their patients. We can therefore see a concurrence in the patient's and healthcare providers' evaluation about the reasons for these fears in the consultation and resulting actions. While some healthcare providers expressed this as "apprehension" rather than "fear," suggesting that the feeling expressed was less intense than the evaluation of fear given by patients, both healthcare providers and patients agreed that emotions were experienced by healthcare providers due to these uncertainties. They also agreed that the emotion could lead to actions of hiding or avoidance on the part of the healthcare provider and that this was unacceptable for the patient. These results concur with recent 
empirical research into healthcare provider's emotions. In a study by Silva and Carvalho (2016), fear was among the most frequent emotions cited by healthcare professionals, along with sadness, anger, and frustration. The study also showed that the majority of healthcare professionals interviewed tried to control their emotions in their professional practices, and that negative emotions like fear often led to actions such as withdrawal and avoidance.

\section{Discussion}

These results show the largely negative role that an emotion like fear can have in the healthcare providerpatient relationship. However this emotion can also be a valuable lens to explore possible solutions. Nussbaum's cognitive-evaluative theory has shown that the object of fear has a relation to flourishing of the person concerned and thus shows something valuable to the persons experiencing these emotions.

\section{The patient's fears and loss of control}

In the case of the patient's fear of their epilepsy, this emotion can be understood as a reasonable fear on the part of the patient. Their loss of control during a seizure represents a risk - to oneself, to others - due to lack of control of the body in its environment. However, given the limited capacity for action when the body is in not in control, these situations can take on a particular intensity and urgency. This is because when a seizure happens whether or not the person loses consciousness, the relationship between the things and persons in one's environment becomes an alien relationship, one in which the person can longer mitigate her movement and agency in that environment. The loss of control of the body is directly tied to an inability of the person to flourish in their environment.

This periodic loss of control experienced during a seizure places considerable responsibility on others. The seizure is the point that the persons in the environment effectively become responsible for that body, as the person is absent or at least "not in control." However, as Nussbaum reminds us, our connection to external goods from infancy is one of ambivalence. Our ambivalence comes from the fact that their provision is uncertain, leading to fear, anger, and frustration when they are not provided, as these goods are largely outside our control. These fears will be augmented when there is an uncertainty of assistance, or if the person witnessing the seizure misunderstands how to help them. Therefore if the person with epilepsy cannot reasonably predict what others will do, they will reasonably fear the coming of seizures as the "sword of Damocles": the need for others is great, but the uncertainty of their assistance even greater. The sword represents the imagery of the seizure, the unpredictability of its impact on the person who is afflicted, but the sword is also the environment, and the dangers lurking in that environment. Persons with epilepsy that cannot trust in those around them live in considerable fear of what will happen when they lose control of their bodies. Thus this fear of the body is not only about the borders surrounding oneself. The emotion is also inextricably tied to our vulnerability and need for others.

For Nussbaum, the problem with fear it is that it is a type of augmented consciousness, highly narrowing. Fear means that the self becomes larger, omnipresent, driving out others. It is thus a shortened vision of our bodies and the things connected to this body. Therefore while fear shows objects important for our flourishing, it can also become a destructive force. Nussbaum tells us the dangers, but also the potentialities of fear. She says, "fear has a strong tendency to get ahead of us, propelling us into selfish, heedless, and antisocial actions...more than other emotions, fear needs careful scrutiny and containment if it is not to turn poisonous." (Nussbaum 2018, p. 5) As fear is a blocking emotion, one that is highly narrowing, it encourages hiding or avoidance. It can therefore lead to other actions not at all representative of the risk at hand, to complicated and new representations of fear, inaccurate or accurate, that can stop the patient from leading an active life. As Nussbaum has shown, previous manifestations of fear can then become the lens through which the person sees and experiences the world. Hybrid theories on emotion have shown how complicated this can become for the person, as making a cognitive judgment on the ridiculousness of fear will not necessarily change the body's reactions toward it (Maiese 2014, p. 49). Thus even if the person evaluates that their fear is out of proportion to the situation, these fears can still lead them to actions to get them out of the fear. This shows the perniciousness of habituated experiences of fear.

The fear of one's disease therefore has considerable consequences in terms of one's life projects and relationships with others. One of these consequences for the person with epilepsy is hiding from any environment in which the person may have a seizure. However, as all environments are ones in which a seizure can occur, this fear can be disastrous for the person with the disease, leading to isolation. This fear can also mutate into new forms. For instance, this fear of the body may lead to new fears, such as a fear of "telling" details of their disease to their doctor, leading to medical errors or inadequate treatment plans. With Nussbaum's theory of emotions, we can understand just how disabling this can be for patients in terms of living well with their illness. We can also understand how it can lead to fears that might negatively affect their treatment plans as well as their relationships with healthcare providers. 


\title{
2. Healthcare provider's fears
}

As elaborated in the results section, healthcare providers often had an ambivalent view of their own emotions experienced in their professional practice. Several explicitly discussed strategies to help their colleagues to overcome their "emotions" in order to be more "professional." Why could there be such a reticence to value emotions in healthcare practices? Nussbaum provides illumination with her link between vulnerability and shame:

\begin{abstract}
"Human beings appear to be the only moral finite beings who wish to transcend their finite. Thus they are the only emotional beings who wish not be emotional, who wish to withhold these acknowledgement of neediness and to design for themselves a life in which these acknowledgements have no place. This means that they frequently learn to reject their own vulnerability and to suppress awareness of the attachments that entail it. We might also say...that they are the only animals for whom neediness is a source of shame, and who take pride in themselves to the extent to which they have allegedly gotten clear of vulnerability." (Nussbaum 2003, p. 137)
\end{abstract}

From Nussbaum's quotation, one way to understand this reticence in healthcare providers to show their emotions is because it represents an exposure of their own vulnerabilities. Performing with emotions was interpreted as non-performance as it exposed them as an emotional rather than a professional worker. As emotions are related to our need for external objects, it also puts into question our autonomy in these professional roles. One healthcare professional even stated explicitly, "we are not professional when our emotions are influencing our decisions." It is expected for healthcare professionals to put aside their emotions in order to attend to the needs of their patients. Finding strategies to limit emotions is taught early on in medical trainings and emotions are viewed as an obstacle for healthcare workers to do their jobs well both at a personal and organizational level. Future healthcare professionals learn strategies to avoid "emotional contagion" from patients and other colleagues in order to be more "efficient" in their healthcare roles. One of the ways suggested by several healthcare providers (notably doctors and nurses) in this research project involved limiting their felt and shown emotions from colleagues, patients, and their families. They said that this allowed them to clearly define their roles and to establish clear rules of conduct to guide their decision-making with other professionals and with their patients. However, despite these strategies, fear and other emotions remain a pervasive part of healthcare work. As Danielle Ofri expresses it in What Doctors Feel,

"Fear is a primal emotion in medicine. Every doctor can tell you of times when she or he was terrified; most can list more episodes than you might wish to hear. This fear of making a mistake and causing harm never goes away, even with decades of experience. It may be most palpable and expressible in neophyte students and interns, but that is merely the first link in a chain that wends its way throughout the life of a doctor. It may be sublimated at times, it may wax and wane, but the fear of harming your patients never departs; it is inextricably linked to the practice of medicine."(Ofri 2013, p.68)

If fear is to a certain extent unavoidable in the practice of medicine, it is worthwhile analyzing this emotion in order to understand what it might show about the healthcare provider's eudaimonia. From our research results, we can see how the object of the fear is related to healthcare providers' ideas of flourishing in their professional roles, in particular their mission to provide the best care for their patient. It is therefore understandable that the moment when the doctor prescribes a "trial and error" healthcare plan or gives bad news to their patient may cause fear. Fear is a signal to healthcare providers to be attentive to uncertainties and risks in the healthcare plan and how it may harm their patients. We can see that fear is not necessarily a negative emotion to be avoided: it shows something of particular importance for healthcare professionals. The very intensity of the experience shows how important this mission is for the healthcare provider.

However fear is also an alarm bell for healthcare providers to the limits of their abilities to provide assistance to their patients. This is due to their own incomplete knowledge but also the limits of modern medicine to treat difficult chronic diseases such as epilepsy. These limitations translate into treatments that are not only "trial and error" but which can also cause considerable side effects in patients without a guarantee of efficacy. Dealing with these uncertainties in the workplace is by no means limited to healthcare workers, but it takes on a particular intensity in healthcare because these decisions can cause harm: in some situations, in can even mean life or death for their patient. These uncertainties are also problematic for healthcare providers because it exposes these limits to others (patients, families, other healthcare providers, and wider society). This puts into difficulty their social standing as experts in the diagnosis and treatment of disease.

With Nussbaum's theory we can now better understand the ambivalence that healthcare providers must feel in these situations, leading to emotions such as fear. The difficulties of providing the best care for their patients due to the limitations of our knowledge of disease and treatment; having to navigate considerable uncertainty due to the need to care for each individual patient; and having to live up to societal expectations of 
healthcare providers. Trying to limit or avoid revealing these emotions was a way to "hide" these uncertainties from others and even from themselves. However, the risk of not recognizing this emotion is ignoring its object and its importance to the healthcare provider's flourishing. In addition, emotions can lead to concrete actions to get away from the fear, such hiding information from the patient in the consultation. Not dealing with these emotions can therefore have repercussions in the healthcare alliance and lead to problems in caring for their patients.

The solution suggested by healthcare providers to "hide" or "limit" this emotion from their patients has also not solved the problem from the patient's perspective, as patients testified that they still witnessed "fear" in their healthcare providers despite attempts to limit it. Patients talked about relationship difficulties because of these witnessed fears. Therefore it will be worthwhile exploring a case study that shows how emotions experienced in the consultation by both the healthcare provider and the patient may affect shared decision making. For illustration, we will take a common situation, namely when the doctor has to give a patient bad news. In the results section, we highlighted a quotation from a healthcare provider who stated that healthcare providers feel fear when confronted with the need to relate bad news to the patient. She said healthcare providers fear these types of situations because of the possible emotional reaction by the patient, which could cause other anxieties or pathologies for them.

In this situation, the emotion testified to by the healthcare provider had a clear object (possible harm to the patient). This was important to her in her mission to provide the best care for her patient, as she had to take into consideration how to balance information sharing with non-maleficence. Therefore one possible solution to this dilemma would be to hide information for the "good" of the patient. However, if this is the choice by the healthcare provider, it will be one in which the healthcare provider decides for the patient, not with the patient. Therefore this decision remains problematic, as the decision to limit information due to the patient's (possible) emotional reaction can also be viewed as a form of paternalism, even if from the healthcare provider's perspective, it meant caring for their patient. Therefore it is worth reconsidering this dilemma in light of Nussbaum's theory.

Nussbaum distinguishes emotions that arise in particular situations (situational emotions) or those that persist in time, which she calls background emotions (Nussbaum 2003, p. 69). Nussbaum says that emotions can be situational yet relatively enduring, and background emotions often become situational owing to different situations. What we can understand from this is that the moment the patient is informed of bad news, such as a diagnosis or the failure of the treatment plan, is the moment in which the object of the fear comes into focus. During this time, the emotion may be expressed into its most intense form and could cause other pathologies or anxieties. However if we take seriously the idea that emotions are cognitive evaluations coming from the patient, then we can accept that it will be reasonable for a patient to have an intense emotional reaction to bad news. Indeed, the very intensity of the emotion will show something of importance to them that could be taken into account during the consultation, such as how this news will affect their life projects or their relationships with loved ones. The emotion experienced in the consultation in its intense form therefore already gives some clues for the healthcare provider of how to care for their patient. Nussbaum also shows that the intensity of an emotion like fear is unlikely to persist in time. These intense emotions will eventually move into the background into some vague, less intense form. From this perspective, there is no reason not to tell the patient given their right to information about their disease. As one healthcare provider expressed it in the interview, "we ask patients to trust us, but if we are not honest, we cannot create a relationship with them."

As we understand that the healthcare provider's fear is related to a dilemma of how to provide the best care for their patient, we can in turn reflect on how the healthcare provider may be able to help the patient mitigate these fears. For instance, as the announcement of bad news may "lead to other pathologies and anxieties," healthcare providers can take seriously this intense emotion lived in its temporality in the consultation in order to help mitigate it once outside of the doctor's office. Understanding that the announcement of bad news might make it difficult for patients to remember or process this information, the healthcare provider may implement strategies to work with this emotion during the consultation, such as asking them why they are scared. This may help open a discussion with them to better understand these fears. It could also help the healthcare provider plan mitigation strategies so that the patient will be less scared in these temporalities, such as planning follow-up appointments to help them better understand the information or developing ways to transmit the information in way that will be less stressful for the patient. These strategies may help the healthcare provider to care for their patient. Another way will be to openly admit treatment failures to their patients. According to one healthcare provider, "to admit that we have failed is important...it's our role to say that I have tried all the different dosages and that we're not sure that a new treatment will help you." Healthcare providers stated that admitting uncertainty also helped patients and their families accept the disease, and enabled a more collaborative relationship, as the patient was better informed about the realistic possibilities of available treatment plans.

From this case study, we can see that recognizing these emotions as cognitive evaluations helps healthcare workers pay attention to what is of particular importance to them and their patients, helping them to flourish in their professional roles by providing their best care for their patient. It may even affect healthcare 
outcomes. According to one neurologist interviewed, "when we help patients (with this fear), they feel better, and they often have less seizures." The way forward for healthcare providers to care for their patients is both to take seriously these emotions in their patients, but also to deal with these fears and apprehension in themselves. However, in order for healthcare providers to be able to recognize and validate these emotions in their professional practices, they will need the support of their institutions. We will explore some possibilities to do so in the discussion section.

\section{Patient assessments of the healthcare provider's fear}

Before closing this discussion, it will be important to distinguish if fear is an accurate evaluation of the healthcare provider and whether or not the emotion expressed could be a less intense feeling such as apprehension. Unlike fear, apprehension is a more vague fear, poorly defined. It is less intense than anxiety or fear which can be punctuated by periods of crisis. When told that patients sometimes think that healthcare providers are "scared" of their patients, one healthcare provider interviewed did not agree with this assessment. According to him, the correct vocabulary to describe what healthcare providers feel during these types of situations was apprehension, rather than fear. The interviewee stated that healthcare providers sometimes "apprehend" something that is going to happen during the consultation in which they did not know how to react, or sometimes that healthcare providers have apprehensions toward certain patients due to their relative status (for instance if the healthcare provider was younger than their patient). If it is more correctly apprehension, it does not necessarily lose its pertinence as it still may lead to actions on the part of the healthcare provider, such as avoiding sharing pertinent information with their patients. Thus it should still be given attention as it affects healthcare decision making.

However there is a (possible) mistranslation in the patient identifying the healthcare provider's emotion as fear. The patient has witnessed nonverbal communication in their healthcare provider which has given them clues to evaluate the unease felt by the healthcare provider toward them. It is possible that this evaluation by the patient could be erroneous (or at least magnified), in particular due to the predominance of the patient's own fears in their overall lives. However, this (possible) mistranslation can also help to better understand the patient experience and how habits of fear can affect the healthcare alliance.

As Nussbaum has argued, following LeDoux (1996), our judgements about the object of our emotions are not always fully within our control. Fear can become the lens through which the person sees the world due to habituated experiences of fear. Persons with epilepsy live with many fearful situations due to their seizures but also because of perceived and felt stigma. The consultation can become another place where fear is felt due to these chronic experiences. Feeling fearful in the consultation, either because of their own fear or because of what they witness in the healthcare providers, remains troubling for the patient. It affects the healthcare alliance, because the patient may not feel comfortable and may avoid or limit communication with their healthcare provider. It can also have an effect on healthcare outcomes, as patients may not share with their healthcare provider important information on the treatment and its side effects due to their fear. For a person living with a stigmatized illness such as epilepsy, a supportive relationship with their healthcare providers is also important because doctors who among the few who were not scared of their condition.

From the research results, we can see that fear and/or apprehension exists in both actors and has repercussions for the healthcare alliance. As Nussbaum has shown, emotions help us evaluate the importance of the object to the person's life projects: thus we can see that the healthcare-provider relationship remains important to both actors' flourishing. Healthcare providers who expressed fears (or apprehensions) were worried about their relationship with their patients and their inabilities to perform well as professionals. They were also fearful of making mistakes or giving information that would harm their patients. In turn this relationship was also important to patient's flourishing, both because the treatment plan would affect their life projects, but also because it could be one in which the healthcare provider was a "sympathetic other." We can see that the intensity of fear shows us how important the healthcare provider-patient relationship remains to both actors, and that taking it seriously in the consultation can help both the patient and the healthcare provider.

\section{Potential solutions}

The discussion has shown the importance of the healthcare alliance to both actors. If the healthcare provider and the patient can enter into a relationship of mutual respect - one in which they do not have to be afraid - it could be that this relationship can become one of trust, rather than one of "hiding." Therefore it is worth considering what potential solutions might help to mitigate this fear for the patient or for the healthcare provider.

Training for healthcare providers on emotions and how to work with emotions in their healthcare practice could release reticence to work with and validate emotions in healthcare practices and among fellow colleagues. One way to do this emotional work is through methodologies like Balint groups, in particular groups organized among equals (such as student-to-student led groups, or colleague-to-colleague led groups in hospital services). Although qualitative studies on the outcomes of such groups remain scarce, Torppa et al. (2008, p. 5) have showed that Balint group methodologies open up the space for future medical students to discuss the 
emotions experienced in relationships with patients and with doctors. As such kinds of groups give a supportive environment to expose and discuss emotions, future and current healthcare professionals cannot only express these emotions with their equals, but also critically analyze their own practices through the input of others in a safe environment.

Another potential solution that could be extended to healthcare providers is the cognitive behavioral therapy currently used in epilepsy treatment to help patients avoid "hiding" behaviors (Leeman-Markowski and Steven C. Schachter 2017). While these and other techniques are valuable to patients, to help them release or at least mitigate their fears, healthcare professionals themselves can equally benefit from this and similar types of support to work with their emotions.

Such emotional work can also take place in the classroom, to help future medical students work through emotions with the support of their fellow students. This kind of work is currently done in some French medical schools through classroom activities such as critical group reflection on their experiences of announcing a diagnosis, in particular in the early years of their medical education when they are still an "intruder" in hospital services. These type of classroom activities gives the means to express, validate and openly discuss emotions felt among peers, to understand that they are not alone and that these emotions can be valued and help them reflect on how to become better professionals. A greater challenge will be to allow such spaces for collective reflection in healthcare institutions.

\section{Limitations and Further Work}

This study sought to identify the emotions present for refractory epilepsy patients and the healthcare providers treating them. Due to the specific nature of epilepsy, its uncontrollable nature, and the intense need of others during seizures, a life with epilepsy is often a life with fear. As fear can in turn become a lens through which patients see the world, fear dominates both emotions lived and seen in others. Thus fear was a particularly intense emotion for this specific group of patients and their healthcare providers.

However, the reflections developed through this specific group of patients may be expanded to further research to other chronic conditions. Due to the unpredictable nature of their conditions, as well as the uncertainty of the treatment plan provided for them, many chronic conditions cause intense emotions in patients and their healthcare providers. Conditions punctuated by unpredictable periods of crisis such as asthma provoke anxiety and fear (Cooper et al., 2007); the anxieties and fears which patients feel due to flares, such as in Crohn's disease (Bannaga and Selinger, 2015) or due to relapses, in diseases such as cancer (Sun et al., 2019) show similarities with the fears felt by patients with epilepsy. Thus it will be worthwhile exploring how the emotions lived in both the management and treatment of these conditions may affect the therapeutic alliance as well as influence healthcare outcomes.

In addition, while the emotion of fear is a strong emotion in this research, identifying other emotions such as shame, anger, happiness or surprise may give new reflections on the doctor-patient relationship, as well as help improve the healthcare relationship for patients and their healthcare providers. It will also be pertinent to limit studies on healthcare provider's emotions to certain temporalities, such as emotions experienced during difficult situations, including telling the diagnosis. In general, should we wish to address healthcare provider emotions, it will be necessary to implement further studies on the temporalities and circumstances which tax the emotional labor of healthcare professionals, as well as address why emotions largely remain an unspoken topic in the practice of medicine.

\section{Conclusion}

This article aimed to identify and unblock certain expressions of fear for patients and their healthcare providers. In understanding that fear remains a highly narrowing emotion and one that can lead to suffering, it gave several possible solutions to mitigate these fears in order to improve the therapeutic alliance. As maintained throughout this article, fear is an important expression of value for healthcare professionals; it shows that they too are vulnerable. It is time to recognize that healthcare providers also have these emotions, and that these emotions are no bad thing, but rather show something of importance to them. Given that these expressions of fear can not only lead to inadequate treatment plans, but also medical errors, finding ways to work with these fears should be a priority for healthcare institutions today. As Martha Nussbaum has shown, emotions form important parts of our judgments about our world and are related to our values and visions of the world. By ignoring emotions in their healthcare practices, are healthcare professionals ignoring their own vulnerabilities, leading to burn-out, brown-out, and situations of conflict with their patients? 


\section{References}

1. Bannaga, Ayman and Christian P. Selinger. 2015. Inflammatory Bowel Disease and Anxiety: Links, Risks, and Challenges Faced. Clinical and Experimental Gastroenterology, 111. https://doi.org/10.2147/CEG.S57982.

2. Bikker, A.P., H. Atherton, H. Brant, T. Porqueddu, J.L. Campbell, A. Gibson, B. McKinstry, C. Salisbury, and S. Ziebland. 2017. Conducting a team-based multi-sited focused ethnography in primary care. BMC Medical Research Methodology 17: 139. https://doi.org/10.1186/s12874-017-0422-5.

3. Callon, Michel, and Vololona Rabeharisoa. 2008. The Growing Engagement of Emergent Concerned Groups in Political and Economic Life: Lessons from the French Association of Neuromuscular Disease Patients. Science, Technology, \& Human Values 33: 230-261. https://doi.org/10.1177/0162243907311264.

4. Carel, Havi, and Ian James Kidd. 2014. Epistemic injustice in healthcare: a philosophical analysis. Medicine, Health Care and Philosophy 17: 529-540. https://doi.org/10.1007/s11019-014-9560-2.

5. Chipidza, Fallon E, Rachel S Wallwork, and Theodore A Stern. 2015. Impact of the Doctor-Patient Relationship. The primary care companion for CNS disorders 17: 10.4088/PCC.15f01840. 26835164. PubMed. https://doi.org/10.4088/PCC.15f01840.

6. Cooper, Cindy L, Glenys D Parry, Carol Saul, Alyn H Morice, Bruce J Hutchcroft, Julia Moore, et Lisa Esmonde. 2007. Anxiety and Panic Fear in Adults with Asthma: Prevalence in Primary Care . BMC Family Practice 8 (1): 62. https://doi.org/10.1186/1471-2296-8-62.

7. Corbeil, Yvon. 2001. Les deux angoisses d' «Être et Temps» et l'«Unbedeutsamkeit. Revue Philosophique de Louvain Quatrièmesérie, tome $99, \mathrm{n}^{\circ} 1$.

8. de Boer, Hanneke M. 2010. Epilepsy stigma: Moving from a global problem to global solutions. Seizure 19: 630-636. https://doi.org/10.1016/j.seizure.2010.10.017.

9. Del Piccolo, Lidia, Erika Pietrolongo, Davide Radice, Carla Tortorella, Paolo Confalonieri, Maura Pugliatti, Alessandra Lugaresi, et al. 2015. Patient Expression of Emotions and Neurologist Responses in First Multiple Sclerosis Consultations. Edited by Markus Reindl. PLOS ONE 10: e0127734. https://doi.org/10.1371/journal.pone.0127734.

10. Dyrbye, Liselotte N., and Tait D. Shanafelt. 2011. Physician Burnout: A Potential Threat to Successful Health Care Reform. JAMA 305. https://doi.org/10.1001/jama.2011.652.

11. Entwistle, Vikki A., and Ian S. Watt. 2013. Treating Patients as Persons: A Capabilities Approach to Support Delivery of Person-Centered Care. The American Journal of Bioethics 13: 29-39. https://doi.org/10.1080/15265161.2013.802060.

12. Goffman, Erving. 1968. Stigma: notes on the management of spoiled identity. Pelican Book A998. Harmondsworth: Penguin Books.

13. Gumuchian, Stephanie T., Sandra Peláez, Vanessa C. Delisle, Marie-Eve Carrier, Lisa R. Jewett, Ghassan El-Baalbaki, Catherine Fortune, et al. 2016. Exploring Sources of Emotional Distress among People Living with Scleroderma: A Focus Group Study. Edited by Shervin Assassi. PLOS ONE 11: e0152419. https://doi.org/10.1371/journal.pone.0152419.

14. Gunther, York H. 2004. The Phenomenology and Intentionality of Emotion. Philosophical Studies: An International Journal for Philosophy in the Analytic Tradition 117, $\mathrm{n}^{\circ}$ 1/2: 43- 55.

15. Ha, Jennifer Fong, and Nancy Longnecker. 2010. Doctor-patient communication: a review. The Ochsner journal 10: 38-43. 21603354. PubMed.

16. Karazivan, Philippe, Vincent Dumez, Luigi Flora, Marie-Pascale Pomey, Claudio Del Grande, Djahanchah Philip Ghadiri, Nicolas Fernandez, Emmanuelle Jouet, Olivier Las Vergnas, and Paule 
Lebel. 2015. The Patient-as-Partner Approach in Health Care: A Conceptual Framework for a Necessary Transition. Academic Medicine 90: 437-441. https://doi.org/10.1097/ACM.0000000000000603.

17. Keddie, S, H Angus-Leppan, T Parker, S Toescu, A Nash, O Adewunmi, and Rsn Liu. 2016. Discussing sudden unexpected death in epilepsy: Are we empowering our patients? A questionnaire survey. JRSM Open 7: 205427041665435. https://doi.org/10.1177/2054270416654358.

18. LeDoux, Joseph E. 1996. The emotional brain: the mysterious underpinnings of emotional life. New York: Simon \& Schuster.

19. Leeman-Markowski, Beth A., and Steven C. Schachter. 2017. Cognitive and Behavioral Interventions in Epilepsy. Current Neurology and Neuroscience Reports 17: 42. https://doi.org/10.1007/s11910-0170752-z.

20. Maiese, Michelle. 2014. How Can Emotions Be Both Cognitive and Bodily? Phenomenology and the Cognitive Sciences 13, n ${ }^{0}$ 4: 513- 31. https://doi.org/10.1007/s11097-014-9373-z.

21. Nummenmaa, L., E. Glerean, R. Hari, et J. K. Hietanen. 2014. Bodily Maps of Emotions ». Proceedings of the National Academy of Sciences $111, \mathrm{n}^{\circ}$ 2: 646- 51. https://doi.org/10.1073/pnas.1321664111.

22. Nussbaum, Martha C. 2003. Upheavals of thought: the intelligence of emotions. 1. paperback ed. Cambridge: Cambridge Univ. Press.

23. Nussbaum, Martha C. 2018. The monarchy of fear: a philosopher looks at our political crisis. First Simon \& Schuster hardcover edition. New York: Simon \& Schuster.

24. Ofri, Danielle. What doctors feel: how emotions affect the practice of medicine. Boston: Beacon Press, 2013.

25. O’Neill, Onora. 2002. Autonomy and trust in bioethics. Gifford Lectures 2001. Cambridge ; New York: Cambridge University Press.

26. Rashid, Marghalara, Carol S. Hodgson, and Thea Luig. 2019. Ten tips for conducting focused ethnography in medical education research. Medical Education Online 24: 1624133. https://doi.org/10.1080/10872981.2019.1624133.

27. Redinbaugh, E. M. 2003. Doctors' emotional reactions to recent death of a patient: cross sectional study of hospital doctors. BMJ 327: 185-0. https://doi.org/10.1136/bmj.327.7408.185.

28. Ridd, Matthew, Alison Shaw, Glyn Lewis, and Chris Salisbury. 2009. The patient-doctor relationship: a synthesis of the qualitative literature on patients' perspectives. The British journal of general practice : the journal of the Royal College of General Practitioners 59: e116-e133. 19341547. PubMed. https://doi.org/10.3399/bjgp09X420248.

29. Ritchie, Jane, and Jane Lewis, ed. 2014. Qualitative research practice: a guide for social science students and researchers. 2nd. ed. London: SAGE.

30. Silva, Joana Vilela Da, and Irene Carvalho. 2016. Physicians Experiencing Intense Emotions While Seeing Their Patients: What Happens? The Permanente journal 20: 15-229. 27479947. PubMed. https://doi.org/10.7812/TPP/15-229.

31. Sirriyeh, R., R. Lawton, P. Gardner, and G. Armitage. 2010. Coping with medical error: a systematic review of papers to assess the effects of involvement in medical errors on healthcare professionals' psychological well-being. BMJ Quality \& Safety 19: e43-e43. https://doi.org/10.1136/qshc.2009.035253.

32. Smeets, Vivian M.J., Brigitte A.G. van Lierop, Jos P.G. Vanhoutvin, Albert P. Aldenkamp, and Frans J.N. Nijhuis. 2007. Epilepsy and employment: Literature review. Epilepsy \& Behavior 10: 354-362. 
https://doi.org/10.1016/j.yebeh.2007.02.006.

33. Sun, Hengwen, Yuan Yang, Jingying Zhang, Ting Liu, Hongmei Wang, Samradhvi Garg, et Bin Zhang. 2019. Fear of Cancer Recurrence, Anxiety and Depressive Symptoms in Adolescent and Young Adult Cancer Patients. Neuropsychiatric Disease and Treatment Volume 15: 857- 65.

https://doi.org/10.2147/NDT.S202432.

34. Stewart, M A. 1995. Effective physician-patient communication and health outcomes: a review. CMAJ : Canadian Medical Association journal = journal de l'Association medicale canadienne 152: 1423-1433. 7728691. PubMed.

35. Taylor, Steven J., and Robert Bogdan. 1998. Introduction to qualitative research methods: a guidebook and resource. 3rd ed. New York: Wiley.

36. Torppa, Martina A., Eeva Makkonen, Camilla Mårtenson, and Kaisu H. Pitkälä. 2008. A qualitative analysis of student Balint groups in medical education: Contexts and triggers of case presentations and discussion themes. Patient Education and Counseling 72: 5-11.

https://doi.org/10.1016/j.pec.2008.01.012.

37. Vazquez, Blanca, and Orrin Devinsky. 2003. Epilepsy and anxiety. Epilepsy \& Behavior 4: 20-25. https://doi.org/10.1016/j.yebeh.2003.10.005. 